\title{
Immunogenicity analysis of conserved fragments in Plasmodium ovale species merozoite surface protein 4
}

\author{
Uwase Juliette \\ Jiangnan University \\ Ruilin Chu \\ Jiangnan University \\ Kokouvi Kassegne \\ Jiangnan University \\ Yao Lei \\ Jiangnan University \\ Feihu Shen \\ Jiangnan University \\ Haitian Fu \\ Jiangnan University \\ Yifan Sun \\ Jiangnan University \\ Yinghua Xuan \\ Jiangnan University \\ Jun Cao \\ Jiangsu Institute of Parasitic Diseases \\ Yang Cheng ( $\square$ woerseng@126.com ) \\ Jiangnan University
}

\section{Research}

Keywords: Plasmodium ovale species, MSP4, Conservation, Immunogenicity, Cross-reactivity, Avidity index

Posted Date: February 18th, 2020

DOI: https://doi.org/10.21203/rs.2.21524/v2

License: (a) (i) This work is licensed under a Creative Commons Attribution 4.0 International License. Read Full License 
Version of Record: A version of this preprint was published at Malaria Journal on March 30th, 2020. See the published version at https://doi.org/10.1186/s12936-020-03207-7. 


\section{Abstract}

Background: There is an urgent need for an effective vaccine to control and eradicate malaria, one of the most serious global infectious diseases. Plasmodium merozoite surface protein 4 (MSP4) has been listed as a blood-stage subunit vaccine candidate for malaria. Plasmodium ovale species (spp.) infection is also a source of malaria burden in tropical regions where it is sometimes mixed with other Plasmodium species. However, little is known about P. ovale spp. MSP4. Methods: The msp4 gene was amplified through polymerase chain reaction using genomic DNA extracted from blood samples of 46 patients infected with P. ovale spp. and amplified products were sequenced. Open reading frames predicted as immunogenic peptides consisting of 119 and 97 amino acids of P. ovale curtisi MSP4 (PocMSP4) and P. ovale wallikeri MSP4 (PowMSP4), respectively, were selected for protein expression. Recombinant proteins (rPoMSP4) were expressed in Escherichia coli, purified, analyzed, and immunized in BALB/c mice. The specificity of anti-MSP4-immunoglubulin (Ig) $\mathrm{G}$ antibodies was evaluated by Western blot and enzyme-linked immunosorbent assays, and cellular immune responses were analyzed via lymphocyte proliferation assays. Results: Full peptide sequences of PocMSP4 and PowMSP4 were completely conserved in all clinical isolates, except in the epidermal growth factor-like domain at the carboxyl terminus where only one mutation was observed in one P. ovale wallikeri isolate. Furthermore, we successfully expressed the truncated pocmsp4 and powmsp4 and purified as $\sim 32 \mathrm{kDa}$ proteins. Our results showed that PocMSP4 and PowMSP4 induced high antibody responses with end-point titers ranging from 1:10,000 to 1:2,560,000 in all immunized mouse groups and with high IgG avidity to PocMSP4 (80.5\%) and PowMSP4 (92.3\%). Furthermore, rPocMSP4 and rPowMSP4 cross-reacted with anti-PowMSP4-specific or anti-PocMSP4-specific antibodies. Additionally, anti-PoMSP4 IgG antibodies showed broad immuno-specificity in reacting against rPoMSP1 and rPoAMA1. Lastly, PocMSP4- and PowMSP4-immunized mice induced cellular immune responses with PocMSP4 (36\%) and PowMSP4 cells (15.8\%) as observed through splenocyte proliferation assays. Conclusion: Our study suggested conservation in PoMSP4 protein sequences and high immunogenicity was observed in rPoMSP4. Furthermore, PocMSP4- and PowMSP4-immunized mice induced cellular immune responses, suggesting that both humoral and cellular immune responses play crucial roles in the protection against any antigen.

\section{Background}

Eradication of malaria is still among the major priorities in the malaria research agenda as the disease continues to kill thousands of people worldwide [1]. In 2017, WHO estimated 219 million cases of malaria and 435,000 deaths, a figure that was assumed too high [2]. Effective vaccine development was urgently required to enhance existing malaria control measures because of the moderate spread of drug and insecticide resistance. Recently, some African countries applied one vaccine RTS, S/AS01; however, this vaccine only targets Plasmodium falciparum [3-5] and might probably be inadequate in areas where a remarkable proportion of patients suffers from Plasmodium vivax or mixed infections. Moreover, three other parasitic species, namely, Plasmodium ovale, Plasmodium malariae, and Plasmodium knowlesi, can also cause malaria infection in human. P. ovale spp. can cause malaria infection in humans but has 
lower incidence compared with $P$. falciparum and $P$. vivax $[6,7]$. Some cases of $P$. ovale spp. infection can occur in endemic areas of malaria where other species co-exist [8,9]; therefore, such evidence should be considered in malaria control strategies. $P$. ovale was separated into two distinct species ( $P$. ovale curtisi and $P$. ovale wallikeri) in 2010 [10-12]. Similar to other malaria parasites of primates, several Anopheles species are able to transmit ovale parasite, which invade reticulocytes and begin the erythrocytic cycle that might last approximately $49 \mathrm{~h} \mathrm{[13].}$

Hosts respond to malaria parasites by generating antibodies against parasite-derived antigens, and naturally acquired immunity is developed after repeated exposure to infections [14]. Notably, antibodies against merozoite antigens play a significant role in conferring immunity against malaria $[15,16]$. Asexual-stage antigens located on apical organelles or on the surfaces of merozoites offer considerable potential as components of vaccines against malaria. Immune responses induced by such vaccines can block the invasion of host erythrocytes through merozoites [17]. Thus, malaria antigens recognized as candidates for vaccine development are generally grouped as pre-erythrocytic, erythrocytic, and transmission-blocking antigens. Antigens in the asexual stages of malaria parasites represent urgent targets for malaria vaccines. Blood-stage vaccines point to target the subsequent disease-causing stage of the Plasmodium life cycle and may provide protection against disease severity, reducing blood stage asexual parasitemia and transmission [18]. Merozoite surface protein 1 (MSP1) and apical membrane antigen (AMA1) are leading blood-stage malaria antigens and considered important vaccine candidates [16], especially due to their association with protection in pre-clinical studies of mice and non-human primates [19-21]. Protection is associated with the induction of high-titer antibodies. Several studies have investigated immune cross-reactivity of antigens in erythrocytic asexual blood stages. For example, immune sera and monoclonal antibodies against AMA1 manifested only limited cross-reactivity between $P$. falciparum and $P$. vivax [22]. Similar studies using sera from people infected with $P$. falciparum and $P$. vivax showed the cross-reactivity of merozoite surface protein 5 (MSP5)-specific antibodies [23].

Evidence of cross-reactivity has been reported for the asexual erythrocytic stages of $P$. falciparum and $P$. vivax antigens, but cross-reactivity of $P$. ovale spp. antigen has limited information.

Merozoite surface protein 4 (MSP4) is a glycosylphosphatidylinositol-anchored protein that contains an epidermal growth factor (EGF)-like domain at the carboxyl terminus [24-26]. MSP4 protein is immunogenic in laboratory animals [27] and crucial for parasite survival [28]. Murine models of malaria showed that this protein can induce protective immunity against lethal challenge and protect against heterologous challenge by a different species of murine malaria [29, 30]. Immunization with recombinant Plasmodium yoelii MSP4/5 in mice, a homolog of MSP4 and its related antigen MSP5, induces protective immune responses against lethal parasite challenge with $P$. yoelii [30,31]; protection is enhanced when MSP4/5 is immunized in combination with $P$. yoelii MSP1 [32]. This finding suggested that MSP4 is a potential malaria vaccine candidate, especially in combination with other antigens. MSP4 immunogenicity is associated with protection in natural infections with $P$. falciparum [33-35]. In addition, MSP4 shows a high degree of conservation among $P$. falciparum isolates [17, 36, 37], supporting its potential consideration as a subunit component for malaria vaccine formulations. However, information on antimalarial properties of $P$. ovale spp. MSP4 is scant. 
In this study, MSP4 sequences were analyzed in clinical isolates of $P$. ovale curtisi and $P$. ovale wallikeri species from infected subjects to assess the conservation and immunogenicity of $P$. ovale spp. MSP4. Furthermore, recombinant PoMSP1 and PoAMA1 antigens were tested against anti-PoMSP4 immunoglobulin $\mathrm{G}(\mathrm{IgG})$ antibodies to evaluate the specificity of PoMSP4 antigens.

\section{Methods}

\section{Malaria samples}

P. ovale curtisi-and P. ovale wallikeri-infected blood samples were obtained from local hospitals in Jiangsu Province (China) between 2012 and 2016 from febrile patients who had recently returned from work in malaria endemic areas of sub-Saharan Africa [38]. Identification of the isolates was confirmed by polymerase chain reaction (PCR) analysis, and parasite species were distinguished using real-time TaqMan PCR [39].

\section{PCR amplification and sequencing of pomsp4 genes}

Genomic DNA extracted from $P$. ovale spp-infected individual blood samples was previously preserved in our laboratory. A total of $46 P$. ovale spp. genomes ( $P$. ovale curtisi, $\mathrm{n}=23$ and $P$. ovale wallikeri, $\mathrm{n}=23$ ) were randomly selected for amplification. Information on the imported $P$. ovale spp. specimens is given in (Additional file 1: Table S1). Full nucleotide sequences of pocmsp4 and powmsp4 were amplified via PCR using primers designed as follows: pocmsp4 forward (5'-ATG AGG GTA CTC CAA TTT TTA TTA C-3'), pocmsp4 reverse (5'-TTA ATT TAT TGA CGC TAA AAT G-3'), powmsp4 forward (5'-ATG AGG GTA CTC CAA TTT TTA TTA C-3'), and powmsp4 reverse (5'- TTA ATT TAT TGA CGC TAA AAT G-3'). Pocmsp 4 (Plasmodium Genomics Resource database, PocGH01_04023000) and powmsp4 (National Center for Biotechnology Information GenBank database, accession number: LT594508.1) were used as reference gene sequences. Reactions were carried out in a volume of $20 \mu \mathrm{L}$, including $1 \mu \mathrm{L}$ of genomic DNA, $0.8 \mu \mathrm{L}$ of each primer $(10 \mu \mathrm{M}), 7.4 \mu \mathrm{L}$ of double-distilled water, 0.5 units of DNA polymerase, and $2 \mathrm{mM}$ deoxynucleoside triphosphate within $10 \mu \mathrm{L}$ of premix (2x Phanta ${ }^{\circledR}$ Max Master Mix, Vazyme). PCR amplification was performed in a Mastercycler (Eppendorf) as follows: denaturation at $95^{\circ} \mathrm{C}$ for $3 \mathrm{~min}$; 35 cycles of $95^{\circ} \mathrm{C}$ for $15 \mathrm{~s}, 51^{\circ} \mathrm{C}$ for $30 \mathrm{~s}$, and $72{ }^{\circ} \mathrm{C}$ for $30 \mathrm{~s}$; and final extension at $72{ }^{\circ} \mathrm{C}$ for $5 \mathrm{~min}$. PCR products were analyzed via $1 \%$ agarose gel electrophoresis, visualized under an ultraviolet transilluminator (Bio-Rad ChemiDoc MP), and sequenced by Genewiz.

\section{Protein bank}

The N-terminal of PoMSP1 and full length of PoAMA1 merozoite surface proteins, which were previously expressed and preserved in our laboratory, were used for specificity tests of PoMSP4 protein-raised antibodies.

\section{Construction of recombinant pomsp4 clones}


PoMSP4-predicted open reading frames (ORFs) without the EGF-like domain consisting of 1-119 (PocMSP4) and 1-97 (PowMSP4) amino acids (in which an ortholog in P. falciparum has been reported as highly immunogenic $[33,34,40])$ were selected. Genomic DNA from $P$. ovale spp. isolates was used as template for PCR amplification of pomsp4 ORFs. Primers were as follows: pocmsp4 forward (5'-ATG AGG GTA CTC CAA TTT TTA TTA C-3'), pocmsp 4 reverse (5'-AGG CGA TGC TAT CGG TTT TG-3'), powmsp4 forward (5'-ATG AGG GTA CTC CAA TTT TTA TTA C-3'), and powmsp4 reverse (5'-TGC TAT ACC TAG GAC ATT TTT ACC C-3'). The reaction was performed in a $20 \mu \mathrm{L}$ volume as described above on a Mastercycler (Eppendorf) with the following temperature profile: initial denaturation at $95^{\circ} \mathrm{C}$ for $3 \mathrm{~min} ; 35$ cycles of 95 ${ }^{\circ} \mathrm{C}$ for $15 \mathrm{~s}, 56{ }^{\circ} \mathrm{C}$ for $30 \mathrm{~s}$, and $72{ }^{\circ} \mathrm{C}$ for $30 \mathrm{~s}$; and a final extension at $72{ }^{\circ} \mathrm{C}$ for 5 min. PCR products were also analyzed as described above.

The amplified fragments were cloned into the pUC57 vector, sequenced by Genewiz on an ABI 3730xI DNA analyzer (Thermo Fisher Scientific) using universal primers (M13F: 5'-TGT AAA ACG ACG GCC AGT3', M13R: 5'-CAG GAA ACA GCT ATG AC-3'), and subcloned into pET32a expression plasmid vector (YouLong Biotech). Recombinant plasmids were transformed into expression host Escherichia coli strain BL21 (DE3) pLysS and sequenced using universal primers T7 through Genewiz.

\section{Protein expression and purification}

E. coli BL21 (DE3) pLysS cells containing recombinant plasmid pET32a ${ }^{\text {pomsp4 }}$ were cultured in LuriaBertani (supplemented with $50 \mathrm{mg} / \mathrm{mL}$ ampicillin) at $37^{\circ} \mathrm{C}$ with shaking until optical density (OD) of 600 $\mathrm{nm}$ reached $0.6-0.8$. The culture was induced with $0.5 \mathrm{mM}$ isopropyl $\beta-\mathrm{D}-1$ thiogalactopyranoside and allowed to grow for another $3 \mathrm{~h}$ at $37^{\circ} \mathrm{C}$. Cells were harvested through centrifugation at $4000 \times g$ for 30 min. Protein purification was performed by YouLong Biotech using the following technique. Thawed cells were suspended in purification buffer (50 mM Tris-HCl [pH 8.0], $300 \mathrm{mM} \mathrm{NaCl}$, and $10 \mathrm{mM}$ imidazole) and lysed by sonication. The insoluble fraction was separated by centrifugation at $15,000 \times g$ for 15 min at 4 ${ }^{\circ} \mathrm{C}$. The soluble fraction was applied to a column containing $1.0 \mathrm{~mL}$ of Ni-nitrilotriacetic acid-agarose (Qiagen) and then washed with $10 \mathrm{~mL}$ of purification buffer containing $20 \mathrm{mM}$ imidazole. Recombinant proteins were eluted from the column with purification buffer containing $250 \mathrm{mM}$ imidazole and then exchanged into Tris- $\mathrm{HCl}$ storage buffer (50 mM Tris-HCl [pH 8.5], $100 \mathrm{mM} \mathrm{NaCl}, 1 \mathrm{mM}$ DTT, $0.1 \mathrm{mM}$ phenylmethylsulfonyl fluoride, and $10 \%$ [v/v] glycerol) using a $30 \mathrm{kDa}$ ultrafiltration tube (Millipore). Proteins were stored at $-80^{\circ} \mathrm{C}$ until use.

\section{Analyses of protein}

The concentration of recombinant proteins ( $\mathrm{rPoMSP} 4$ ) was determined through the Bradford method using bovine serum albumin (BSA) as standard (Bradford protein assay kit, Solarbio). Purified proteins were analyzed by $12 \%$ sodium dodecyl sulfate-polyacrylamide gel electrophoresis (SDS-PAGE) and Coomassie brilliant blue staining (Beyotime Biotech) to assess the expression level and immunoreactivity. The separated proteins from SDS-PAGE were electrophorectically transferred onto a polyvinylidene difluoride (PVDF) membrane (Immobilon) and blocked overnight in Tris-buffered saline 
with $0.1 \%$ Tween-20 (TBST) containing $5 \%$ skimmed milk at $4{ }^{\circ} \mathrm{C}$. The membranes were probed with antiHis antibody (ABclonal) at 1:5000 dilution along with primary antibody dilution buffer (Meilunbio) overnight at $4{ }^{\circ} \mathrm{C}$. Membranes were washed three times with $0.1 \%$ TBST and treated with horseradish peroxidase (HRP)-conjugated goat anti-mouse IgG (Cowin Biotech) at 1:5000 dilution for 90 min. Finally, the membranes were analyzed with a ChemiDoc MP imaging system (Bio-Rad).

\section{Antibody raising and immunodetection}

Six- to eight-week-old female BALB/c mice were used for immunizations as follows. Mice were grouped into the rPoMSP4-immunized ( $n=5$ per group) and negative control groups ( $n=3$ per group). Each mouse was intraperitoneally injected with $50 \mu \mathrm{g}$ of rPocMSP4, rPowMSP4, or PBS, all of which were diluted in PBS with complete Freund's adjuvant (Sigma). An equal volume of antigen with incomplete Freund's adjuvant (Sigma) was used for subsequent boosters, which were administered on days 21 and 42 postimmunization intraperitoneally. The control group was administered an equal amount of PBS and adjuvant. Mouse blood samples were collected from the tip of the tail on days $0,7,14,28,35$, and 49 . Sera were obtained via centrifugation for $20 \mathrm{~min}$ at $2000 \times \mathrm{rpm}$ and stored at $-80^{\circ} \mathrm{C}$.

Purified rPoMSP4 was tested against sera from rPocMSP4- or rPowMSP4-infected mice to assess antiPoMSP4 IgG antibodies through Western blot analysis. During the assays, PVDF membranes were incubated with antisera (1:2000 dilutions) from the rPoMSP4-immunized group or negative control group, followed by HRP-conjugated goat anti-mouse IgG (Cowin Biotech) at 1:5000 dilution.

\section{Anti-PoMSP4 antibody specificity}

Levels of IgG antibodies targeting PoMSP4 in mouse sera were detected via enzyme-linked immunosorbent assays (ELISA). In brief, 96-well ELISA plates were coated with $50 \mathrm{ng}$ of rPoMSP4 antigen dissolved in coating buffer solution $(15 \mathrm{mM}$ sodium carbonate and $35 \mathrm{mM}$ sodium bicarbonate in distilled water) overnight at $4{ }^{\circ} \mathrm{C}$. After washing three times with PBS containing $0.1 \%$ of Tween-20 (PBST), the plates were blocked with 1\% BSA in PBS and incubated at room temperature for $2 \mathrm{~h}$. Thereafter, individual mouse sera $(100 \mu \mathrm{L})$ diluted at different dilutions were added on the plate and incubated at room temperature for $2 \mathrm{~h}$. The plates were washed again three times with PBST and HRPconjugated goat anti-mouse IgG antibodies (Southern Biotech) at 1:5000 dilution and incubated for $1 \mathrm{~h}$ $30 \mathrm{~min}$ at room temperature. The plates were washed three times with PBST and incubated with 3, 3', 5, 5'-tetramethylbenzidine (Invitrogen) substrate for a few minutes in the dark, and $2 \mathrm{M} \mathrm{H}_{2} \mathrm{SO}_{4}$ was added to stop the reaction. The absorbance at OD of $450 \mathrm{~nm}$ was measured using a microplate reader (Synergy, BioTeK). Furthermore, anti-PoMSP4 IgG antibodies were tested against rPoMSP1 and rPoAMA1 antigens via ELISA to test for the specificity of antibodies.

\section{Lymphocyte proliferation assays}

Lymphocyte proliferation was measured using a cell counting kit-8 (CCK-8, Beyotime Biotech). A certain amount of $5 \times 10^{5}$ cells/well of PoMSP4- and PBS-immunized cells was treated with $10 \mu \mathrm{L}$ of PocMSP4 
$(5 \mu \mathrm{g} / \mathrm{mL}), 10 \mu \mathrm{L}$ of PowMSP4 $(5 \mu \mathrm{g} / \mathrm{mL})$, or $10 \mu \mathrm{L}$ of concanavalin A (Con A, $2 \mu \mathrm{g} / \mathrm{mL})$, which served as a positive control, in 96-well flat-bottom microtiter plates and then incubated for $72 \mathrm{~h}$ at $37{ }^{\circ} \mathrm{C}$ with $5 \%$ $\mathrm{CO}_{2}$ in an incubator. Thereafter, $10 \mu \mathrm{L}$ of CCK-8 was added to each well, and the plates were incubated for $2 \mathrm{~h}$ at $37^{\circ} \mathrm{C}$ and measured at $450 \mathrm{~nm}$ using a microplate reader.

\section{Sequence alignment and data analysis}

Full nucleotide sequences of pomsp4 genes from all clinical isolates were translated to the deduced amino acid sequences using the MegAlign module of Lasergene 7 software package (DNAstar) and then aligned with reference sequences to assess the conservation within PoMSP4. Amino acid sequences of the segments of PocMSP4 and PowMSP4 isolates were aligned with those of the PocGH01_04023000 and LT594508.1 reference strains, respectively. Sequence alignment for all $P$. ovale spp. isolates was performed using MEGA v.7.0 software.

Statistical analysis and graphing were conducted using GraphPad Prism software version 5.0 (Graph Pad software, Inc.). SPSS v.16.0 was performed to analyze cross-reaction and antibody responses. Student's t-test with probability $(P)$ value of $<0.05$ indicated a significant difference.

\section{Results}

\section{Analysis of amplified pomsp4 genes revealed the conservation of amino acids in isolate sequences}

The full length of pomsp4 genes was successfully amplified from the genomic DNA of 23 P. ovale curtisiand $23 P$. ovale wallikeri-infected individuals. A phylogenetic tree was reconstructed through the neighborjoining method based on human, non-human primate, murine, and avian malaria species to infer genetic relationships of pocmsp4 and powmsp4. Phylogenetic analysis of gene sequences of pocmsp4 and powmsp 4 revealed $99 \%$ similarity (Fig. 1). The $m s p 4$ gene ID number of the plasmodium species included in the analyses is provided in Additional file 2: Table S2. The alignments of PoMSP4 amino acid sequences from both subspecies showed that no amino acid mutation occurred among all isolate samples from 17 different countries in Sub-Saharan Africa (Additional file 3: Figure S1), suggesting the complete conservation of PoMSP4, which was consistent with previous findings, especially in $P$. falciparum orthologs $[17,36,37]$. Only one mutation was observed in the EGF-like domain at the carboxyl terminus in one P. ovale wallikeri isolate (from Uganda); however, this single mutation could not affect the antigenicity of MSP4 proteins because EGF domains have relatively poorly immunogenicity $[33,34,40]$.

\section{Expression, purification, and analysis of recombinant PoMSP4 proteins}

The selected pomsp4 fragments were successfully amplified in isolates through PCR, generating single PCR products with the expected size of $360 \mathrm{bp}$ for pocmsp 4 and $294 \mathrm{bp}$ for powmsp4. Direct sequencing of purified PCR fragments showed no superimposed signal on the electropherograms for pomsp4 (Fig. 2a). 
The molecular weight of expressed PocMSP4 and PowMSP4 ORFs was estimated to be approximately $32 \mathrm{kDa}$, which was consistent with that obtained in purified proteins as shown in SDS-PAGE analysis with Coomassie blue staining (Fig.2b). Immunoblotting analysis that used anti-His tag antibody confirmed that rPoMSP4 was expressed (Fig. 2c).

\section{Micederived antibodies against PoMSP4 recognized the recombinant proteins}

We elaborated an immunoblot specific to $32 \mathrm{kDa}$ bands corresponding to the sizes of the two rPoMSP4 proteins to determine whether mice anti-rPoMSP4 antibodies can identify rPoMSP4 (Fig. 3a). The antibody responses of the sera of immunized mice were potent against rPoMSP4, suggesting that PoMSP4 could induce immune responses and was immunogenic in mice. As a negative control, no reactivity was noted in the normal and PBS-immunized mice (Fig. 3b). Furthermore, cross-reactivity was tested using anti-rPoMSP4-immune mouse sera with each of the rPoMSP4 proteins (Fig. 3c). These results showed that mice anti-rPocMSP4 and anti-rPowMSP4 antibodies could recognize rPowMSP4 and rPocMSP4 antigens, respectively.

\section{Immune responses against rPoMSP4 in mice}

Antibody responses from all groups of mice were measured through ELISA using the same recombinant proteins constructed as the solid phase coating antigen. ELISA results showed that antibodies against PoMSP4 in mice were detected 1 week after the primary booster. A response was detected at day 7 postimmunization and continued to rise throughout the whole immunization period (Fig. 4a). Mean serum antibody titers were evaluated through ELISA at 49 days after the first immunization. Similarly, PocMSP4 and PowMSP4 induced a high antibody response with end-point titers ranging from 1:10,000 to 1:2,560,000 (Fig. 4b). Anti-rPocMSP4 and anti-rPowMSP4 antibodies in all immunized mouse groups exhibited high avidity indexes (Als), and the average Als of anti-rPocMSP4 and anti-rPowMSP4 IgGs were $80.5 \%$ and $92.3 \%$, respectively (Fig. 4 C).

\section{Cross-reactivity of rPoMSP4 proteins with anti-rPoMSP4 antibodies}

ELISA was used to investigate whether the antibodies from rPocMSP4-immunized mice can combine with PowMSP4 protein and whether the antibody of rPowMSP4-immunized mice can combine with PocMSP4 protein. The results showed that mouse anti-rPocMSP4 or anti-rPowMSP4 antibodies could recognize rPocMSP4 and rPowMSP4, with no significant difference ( $p=0.5758$; Fig. $4 d$ ), suggesting the high specificity of both anti-PoMSP4 antibodies.

\section{Lymphocyte proliferation assays}

PocMSP4 and PowMSP4 protein antigens were able to induce high antibody levels in mice. Therefore, we used spleen lymphocyte proliferation assays to test whether these antigens can induce cellular immune responses. The proliferation assay was performed to assess the influence of the splenocyte proliferative response to rPoMSP4 proteins in vitro under rPocMSP4, rPowMSP4, and ConA (positive control) 
stimulations. Results showed that rPoMSP4-induced cell proliferation was estimated at $36 \%$ for PocMSP4 and $15.8 \%$ for rPowMSP4 (Fig. 4e).

\section{Specificity of PoMSP4-derived antisera}

The specificity and reactivity of antibodies raised against PoMSP4 proteins were evaluated by testing rPoAMA1 or rPoMSP1 proteins with mouse anti-rPoMSP4 sera from each immunized group using ELISA. All sera from mice immunized with rPoMSP4 recognized the antigen when the ELISA plate was sensitized with rPoAMA1 proteins (Figs. 5a and 5b), and no significant difference in cross-reactivity was observed $(p>0.05)$. However, significant differences in cross-reaction were detected between rPocMSP1 to antirPocMSP4 sera and rPocMSP4 to anti-rPocMSP4 sera $(p<0.0001)$ whereas no significant difference was observed between rPocMSP4 and PowMSP1 to anti-rPocMSP4 sera ( $p=0.9063$; Fig. $5 c$ ). In addition, cross-reactivity was observed between rPocMSP1 to anti-rPowMSP4 sera and rPowMSP4 to antirPowMSP4 sera $(p<0.0001)$ and between rPowMSP4 and PowMSP1 to anti-rPowMSP4 sera $(p<0.0430$; Fig. $5 d$ ). In summary, anti-rPoMSP4 sera cross-reacted against rPocAMA1 or rPowAMA1, and rPowMSP1 proteins by contrast, they showed low reactivity with rPocMSP1 proteins. This result suggested that rPoMSP4 antigens were able to generate antibodies with broad immune responses against such important proteins (known to be associated with red blood cell invasion [16]), making them attractive candidates to induce a polyclonal immune response.

\section{Discussion}

The effectiveness of malaria vaccines mostly depends on the high degree of conservation and excellent level of immunogenicity. Here, we analyzed 46 P. ovale spp. clinical isolates imported from Africa. Amplification and sequencing results showed that the full lengths of pomsp4 nucleotide and PoMSP4 amino acid sequences (from 23 P. ovale curtisi isolates and $23 P$. ovale wallikeri isolates) were completely conserved. These results were in accordance with other reports that showed a high degree of conservation of $m s p 4$ orthologs in P. falciparum isolates [37, 41, 42]. In addition, the high degree of conservation suggested that pomsp4 can be useful in PCR-based diagnostic testing for $P$. ovale spp.

The development of blood-stage vaccines against malaria focuses on infected erythrocytes or proteins, which are accessible for antibodies, expressed on the surface of the parasites. Thus, humoral immune responses are important against malaria parasites because they play essential roles in protecting against blood-stage malaria [43]. Antibody responses against blood-stage antigens are known for their importance in protecting against malaria [44], and our results showed that recombinant PoMSP4 proteins were immunogenic in mice. IgG antibody titers elicited by PocMSP4 and PowMSP4 fragments were substantially higher than those found in the control group (PBS), and sera from immunized mice showed positive reactivity with rPocMSP4 and rPowMSP4 proteins. Cross-reaction between rPocMSP4 and rPowMSP4 was detected through ELISA and Western blot analyses. These results suggested that rPoMSP4 shared similar antigenic determinants that could enable the measurement of species-specific efficacy in vaccine trials. This high cross-reaction between the two proteins addressed the possibility that 
both proteins may be used together for vaccine design. However, this result would need future studies to address the possibility of vaccine development or functional studies. Antibody avidity seems to play an important role in protective immunity [45]. Our results indicated that rPocMSP4 and rPowMSP4 induced high-avidity antibodies (PocMSP4: $80.50 \%$ and PowMSP4: 92.32\%). These findings suggested that MSP4 is a valid model for understanding the immune response in mice. MSP1 and AMA1 proteins are currently being developed as subunits for the development of malaria vaccines [20,46, 47]. In our study, the crossantisera reaction between PoMSP4 and PoAMA1 or PoMSP1 was observed, that is, anti-PoMSP4 antiserum cross-reacted with recombinant PoAMA1 and PoMSP1 in ELISA. This ability of PoMSP4 antigens to generate antibodies with broad immune responses against such important proteins make them attractive candidates to induce a polyclonal immune response.

Lymphocytes play an important role in the immune system because these cells determine the specificity of the immune response to infectious microorganisms and other foreign substances. Lymphocyte proliferation assays are widely used to measure cell-mediated T-cell immunity and responses to specific antigens $[48,49]$. Besides humoral responses, the cellular immune response is also an important indicator for evaluating the immunogenicity of a vaccine candidate. As demonstrated by our results, PocMSP4 and PowMSP4 proteins could induce the cellular immune response in mice, suggesting that humoral and cellular immune responses play crucial roles in the protection against any antigen.

\section{Conclusion}

Immunization with conserved rPoMSP4 protein fragments resulted in a remarkable humoral immune response. Cross-reaction between rPocMSP4 and rPowMSP4 proteins or between rPoAMA1 and rPoMSP1 proteins to anti-rPoMSP4 was detected, suggesting that these proteins shared similar antigenic determinants. PoMSP4 could induce cellular immune responses, suggesting that these fragments of $P$. ovale spp. may be more widely evaluated as potential vaccine candidates, although further study needs be carried out to validate its potential and limitations.

\section{Abbreviations}

MSP4: Merozoite surface protein4

rPoMSP4: recombinant PoMSP4

PCR: polymerase chain reaction

ELISA: enzyme-linked immunosorbent assays

\section{Declarations}

\section{Ethics approval and consent to participate}


This study was approved by the Ethics Committee, Jiangsu Provincial Key Laboratory on Parasite and Vector Control Technology, Jiangsu Institute of Parasitic Diseases (JIPD) (IRB00004221), Wuxi, China. Informed consent was obtained from all of the participants, and the animal trial was approved by the Animal Ethics Committee, Jiangnan University (JN. No20180615t0900930[100]).

\section{Consent for publication}

Not applicable

\section{Availability of data and materials}

The data supporting the conclusions of this article are included within the article and its additional files.

\section{Competing interests}

The authors declare that they have no competing interests.

\section{Funding}

This work was financially supported by the National Natural Science Foundation of China under Grants (81601787, 81871681), by the Natural Science Foundation of Jiangsu Province under Grants (BK20160192, BK20150001), by the Jiangsu Provincial Key Research and Development Program under Grants (BE2016631), by the Fundamental Research Funds for the Central Universities funded by the Ministry of Education of China under Grants (JUSRP51710A), by the Bill and Melinda Gates Foundation under Grants (OPP1161962), by the national first-class discipline program of Food Science and Technology under Grants (JUFSTR20180101), by the Science and Technology Innovation Project for College Students of Jiangnan University under Grants (1285210232175260), and by the Jiangsu Provincial Project of Invigorating Health Care through Science, Technology and Education.

\section{Authors' contributions}

YC and JC conceived this study. UJ, RLC, YL, and FHS designed, performed the experiments, and analyzed the data. UJ and KK wrote the manuscript. YHX, HTF and YFS reviewed the manuscript. All authors read and approved the final manuscript.

\section{Acknowledgment}

We would like to acknowledge all study participants and we are particularly grateful to all patients who donated their blood samples.

\section{Authors' information}

${ }^{1}$ Laboratory of Pathogen Infection and Immunity, Department of Public Health and Preventive Medicine; Wuxi School of Medicine, Jiangnan University, Wuxi, Jiangsu, People's Republic of China; ${ }^{2}$ Key Laboratory 
of National Health and Family Planning Commission on Parasitic Disease Control and Prevention, Jiangsu Provincial Key Laboratory on Parasite and Vector Control Technology, Jiangsu Institute of Parasite Diseases, Wuxi, Jiangsu, People' s Republic of China.

\section{References}

1. Kassegne K, Zhang T, Chen SB, Xu B, Dang ZS, Deng WP, Abe EM, Shen HM, Hu W, Guyo TG, et al: Study roadmap for high-throughput development of easy to use and affordable biomarkers as diagnostics for tropical diseases: a focus on malaria and schistosomiasis. Infect Dis Poverty 2017, 6:130.

2. WHO. World Malaria Report 2018. Geneva: World Health Organization; 2018

3. Vandoolaeghe P, Schuerman L: The RTS,S/AS01 malaria vaccine in children aged 5-17 months at first vaccination. The Pan African medical journal 2018, 30:142-142.

4. Dobaño C, Ubillos I, Jairoce C, Gyan B, Vidal M, Jiménez A, Santano R, Dosoo D, Nhabomba AJ, Ayestaran A, et al: RTS,S/AS01E immunization increases antibody responses to vaccine-unrelated Plasmodium falciparum antigens associated with protection against clinical malaria in African children: a case-control study. BMC medicine 2019, 17:157-157.

5. Agnandji ST, Lell B, Soulanoudjingar SS, Fernandes JF, Abossolo BP, Conzelmann C, Methogo BG, Doucka Y, Flamen A, Mordmuller B, et al: First results of phase 3 trial of RTS,S/AS01 malaria vaccine in African children. N Engl J Med 2011, 365:1863-1875.

6. Kassegne K, Abe EM, Cui YB, Chen SB, Xu B, Deng WP, Shen HM, Wang Y, Chen JH, Zhou XN: Contribution of Plasmodium immunomics: potential impact for serological testing and surveillance of malaria. Expert Rev Proteomics 2018.

7. Collins WE, Jeffery GM: Plasmodium ovale: parasite and disease. Clin Microbiol Rev 2005, 18:570581.

8. Doderer-Lang C, Atchade PS, Meckert L, Haar E, Perrotey S, Filisetti D, Aboubacar A, Pfaff AW, Brunet $\mathrm{J}$, Chabi NW, et al: The ears of the African elephant: unexpected high seroprevalence of Plasmodium ovale and Plasmodium malariae in healthy populations in Western Africa. Malar J 2014, 13:240.

9. Rutledge GG, Böhme U, Sanders M, Reid AJ, Cotton JA, Maiga-Ascofare O, Djimdé AA, Apinjoh TO, Amenga-Etego $L$, Manske $M$, et al: Plasmodium malariae and $P$. ovale genomes provide insights into malaria parasite evolution. Nature 2017, 542:101-104.

10. Sutherland CJ: Persistent Parasitism: The Adaptive Biology of Malariae and Ovale Malaria. Trends in Parasitology 2016, 32:808-819.

11. Oguike MC, Betson M, Burke M, Nolder D, Stothard JR, Kleinschmidt I, Proietti C, Bousema T, Ndounga $\mathrm{M}$, Tanabe $\mathrm{K}$, et al: Plasmodium ovale curtisi and Plasmodium ovale wallikeri circulate simultaneously in African communities. Int $\mathrm{J}$ Parasitol 2011, 41:677-683.

12. Sutherland CJ, Tanomsing N, Nolder D, Oguike M, Jennison C, Pukrittayakamee S, Dolecek C, Hien TT, do Rosario VE, Arez AP, et al: Two nonrecombining sympatric forms of the human malaria parasite 
Plasmodium ovale occur globally. J Infect Dis 2010, 201:1544-1550.

13. Collins WE, Jeffery GM: Plasmodium ovale: parasite and disease. Clinical microbiology reviews 2005, 18:570-581.

14. Ellis RD, Sagara I, Doumbo O, Wu Y: Blood stage vaccines for Plasmodium falciparum: current status and the way forward. Hum Vaccin 2010, 6:627-634.

15. Barua P, Beeson JG, Maleta K, Ashorn P, Rogerson SJ: The impact of early life exposure to Plasmodium falciparum on the development of naturally acquired immunity to malaria in young Malawian children. 2019, 18:11.

16. Kassegne K, Abe EM, Chen JH, Zhou XN: Immunomic approaches for antigen discovery of human parasites. Expert Rev Proteomics 2016, 13:1091-1101.

17. Benet A, Tavul L, Reeder JC, Cortes A: Diversity of Plasmodium falciparum vaccine candidate merozoite surface protein 4 (MSP4) in a natural population. Mol Biochem Parasitol 2004, 134:275280 .

18. Illingworth JJ, Alanine DG, Brown R, Marshall JM, Bartlett HE, Silk SE, Labbé GM, Quinkert D, Cho JS, Wendler JP, et al: Functional Comparison of Blood-Stage Plasmodium falciparum Malaria Vaccine Candidate Antigens. Frontiers in immunology 2019, 10:1254-1254.

19. Biswas S, Spencer AJ, Forbes EK, Gilbert SC, Holder AA, Hill AV, Draper SJ: Recombinant viralvectored vaccines expressing Plasmodium chabaudi AS apical membrane antigen 1: mechanisms of vaccine-induced blood-stage protection. J Immunol 2012, 188:5041-5053.

20. Elias SC, Choudhary P, de Cassan SC, Biswas S, Collins KA, Halstead FD, Bliss CM, Ewer KJ, Hodgson SH, Duncan CJA, et al: Analysis of human B-cell responses following ChAd63-MVA MSP1 and AMA1 immunization and controlled malaria infection. Immunology 2014, 141:628-644.

21. Dutta S, Sullivan JS, Grady KK, Haynes JD, Komisar J, Batchelor AH, Soisson L, Diggs CL, Heppner DG, Lanar DE, et al: High antibody titer against apical membrane antigen-1 is required to protect against malaria in the Aotus model. PLoS One 2009, 4:e8138.

22. Igonet S, Vulliez-Le Normand B, Faure G, Riottot MM, Kocken CH, Thomas AW, Bentley GA: Crossreactivity studies of an anti-Plasmodium vivax apical membrane antigen 1 monoclonal antibody: binding and structural characterisation. J Mol Biol 2007, 366:1523-1537.

23. Woodberry T, Minigo G, Piera KA, Hanley JC, de Silva HD, Salwati E, Kenangalem E, Tjitra E, Coppel $\mathrm{RL}$, Price RN, et al: Antibodies to Plasmodium falciparum and Plasmodium vivax merozoite surface protein 5 in Indonesia: species-specific and cross-reactive responses. J Infect Dis 2008, 198:134-142.

24. Marshall VM, Silva A, Foley M, Cranmer S, Wang L, McColl DJ, Kemp DJ, Coppel RL: A second merozoite surface protein (MSP-4) of Plasmodium falciparum that contains an epidermal growth factor-like domain. Infect Immun 1997, 65:4460-4467.

25. Gilson PR, Nebl T, Vukcevic D, Moritz RL, Sargeant T, Speed TP, Schofield L, Crabb BS: Identification and stoichiometry of glycosylphosphatidylinositol-anchored membrane proteins of the human malaria parasite Plasmodium falciparum. Mol Cell Proteomics 2006, 5:1286-1299. 
26. Wang L, Black CG, Marshall VM, Coppel RL: Structural and antigenic properties of merozoite surface protein 4 of Plasmodium falciparum. Infect Immun 1999, 67:2193-2200.

27. Wang L, Black CG, Marshall VM, Coppel RL: Structural and antigenic properties of merozoite surface protein 4 of Plasmodium falciparum. Infection and immunity 1999, 67:2193-2200.

28. Sanders PR, Kats LM, Drew DR, O'Donnell RA, O'Neill M, Maier AG, Coppel RL, Crabb BS: A set of glycosylphosphatidyl inositol-anchored membrane proteins of Plasmodium falciparum is refractory to genetic deletion. Infection and immunity 2006, 74:4330-4338.

29. Goschnick MW, Black CG, Kedzierski L, Holder AA, Coppel RL: Merozoite surface protein 4/5 provides protection against lethal challenge with a heterologous malaria parasite strain. Infection and immunity 2004, 72:5840-5849.

30. Kedzierski L, Black CG, Coppel RL: Immunization with recombinant Plasmodium yoelii merozoite surface protein 4/5 protects mice against lethal challenge. Infect Immun 2000, 68:6034-6037.

31. Goschnick MW, Black CG, Kedzierski L, Holder AA, Coppel RL: Merozoite surface protein 4/5 provides protection against lethal challenge with a heterologous malaria parasite strain. Infect Immun 2004, 72:5840-5849.

32. Kedzierski L, Black CG, Goschnick MW, Stowers AW, Coppel RL: Immunization with a combination of merozoite surface proteins $4 / 5$ and 1 enhances protection against lethal challenge with Plasmodium yoelii. Infect Immun 2002, 70:6606-6613.

33. Chittibabu G, Ma C, Netter HJ, Noronha SB, Coppel RL: Production, characterization, and immunogenicity of a secreted form of Plasmodium falciparum merozoite surface protein 4 produced in Bacillus subtilis. App/ Microbiol Biotechnol 2014, 98:3669-3678.

34. Wang L, Richie TL, Stowers A, Nhan DH, Coppel RL: Naturally acquired antibody responses to Plasmodium falciparum merozoite surface protein 4 in a population living in an area of endemicity in Vietnam. Infect Immun 2001, 69:4390-4397.

35. Perraut R, Varela ML, Joos C, Diouf B, Sokhna C, Mbengue B, Tall A, Loucoubar C, Toure A, Mercereau-Puijalon O: Association of antibodies to Plasmodium falciparum merozoite surface protein-4 with protection against clinical malaria. Vaccine 2017, 35:6720-6726.

36. Wang L, Marshall VM, Coppel RL: Limited polymorphism of the vaccine candidate merozoite surface protein 4 of Plasmodium falciparum. Mol Biochem Parasitol 2002, 120:301-303.

37. Polson HE, Conway DJ, Fandeur T, Mercereau-Puijalon O, Longacre S: Gene polymorphism of Plasmodium falciparum merozoite surface proteins 4 and 5. Mol Biochem Parasitol 2005, 142:110115.

38. Chu R, Zhang X, Xu S, Chen L, Tang J, Li Y, Chen J, Xuan Y, Zhu G, Cao J, Cheng Y: Limited genetic diversity of N-terminal of merozoite surface protein-1 (MSP-1) in Plasmodium ovale curtisi and $\mathrm{P}$. ovale wallikeri imported from Africa to China. Parasites \& vectors 2018, 11:596-596.

39. Cao Y, Wang W, Liu Y, Cotter C, Zhou H, Zhu G, Tang J, Tang F, Lu F, Xu S, et al: The increasing importance of Plasmodium ovale and Plasmodium malariae in a malaria elimination setting: an 
observational study of imported cases in Jiangsu Province, China, 2011-2014. Malaria journal 2016, 15:459-459.

40. de Silva HD, Saleh S, Kovacevic S, Wang L, Black CG, Plebanski M, Coppel RL: The antibody response to Plasmodium falciparum Merozoite Surface Protein 4: comparative assessment of specificity and growth inhibitory antibody activity to infection-acquired and immunization-induced epitopes. Malar $J$ 2011, 10:266.

41. Wang L, Marshall VM, Coppel RL: Limited polymorphism of the vaccine candidate merozoite surface protein 4 of Plasmodium falciparum. Molecular and Biochemical Parasitology 2002, 120:301-303.

42. de Silva HD, Saleh S, Kovacevic S, Wang L, Black CG, Plebanski M, Coppel RL: The antibody response to Plasmodium falciparum Merozoite Surface Protein 4: comparative assessment of specificity and growth inhibitory antibody activity to infection-acquired and immunization-induced epitopes. Malaria journal 2011, 10:266-266.

43. Marsh K, Kinyanjui S: Immune effector mechanisms in malaria. Parasite Immuno/ 2006, 28:51-60.

44. Daly TM, Long CA: Humoral response to a carboxyl-terminal region of the merozoite surface protein1 plays a predominant role in controlling blood-stage infection in rodent malaria. $\mathrm{J} / \mathrm{mmuno} / 1995$, 155:236-243.

45. Ssewanyana I, Arinaitwe E, Nankabirwa JI, Yeka A, Sullivan R, Kamya MR, Rosenthal PJ, Dorsey G, Mayanja-Kizza H, Drakeley $\mathrm{C}$, et al: Avidity of anti-malarial antibodies inversely related to transmission intensity at three sites in Uganda. Malaria journal 2017, 16:67-67.

46. Wang Y-N, Lin M, Liang X-Y, Chen J-T, Xie D-D, Wang Y-L, Ehapo CS, Eyi UM, Huang H-Y, Wu J-L, et al: Natural selection and genetic diversity of domain I of Plasmodium falciparum apical membrane antigen-1 on Bioko Island. Malaria journal 2019, 18:317-317.

47. Jahangiri F, Jalallou N, Ebrahimi M: Analysis of Apical Membrane Antigen (AMA)-1 characteristics using bioinformatics tools in order to vaccine design against Plasmodium vivax. Infection, Genetics and Evolution 2019, 71:224-231.

48. Hines SE, Pacheco K, Maier LA: The role of lymphocyte proliferation tests in assessing occupational sensitization and disease. Curr Opin Allergy Clin Immunol 2012, 12:102-110.

49. Nikbakht M, Pakbin B: Evaluation of a new lymphocyte proliferation assay based on cyclic voltammetry; an alternative method. 2019, 9:4503.

\section{Additional File Legends}

Additional file 1: Table S1.Information on imported $P$. ovale curtisi and $P$. ovale wallikeri used in this study.

Additional file 2: Table S2. The msp4 Gene ID number of other Plasmodium species

Additional file 3: Figure S1. Alignments for the amino acid sequences of $P$. ovale curtisi and $P$. ovale wallikeri MSP4 in all amplified clinical isolates a. PocMSP4 amino acid sequences b. PowMSP4 amino acid sequences 


\section{Figures}

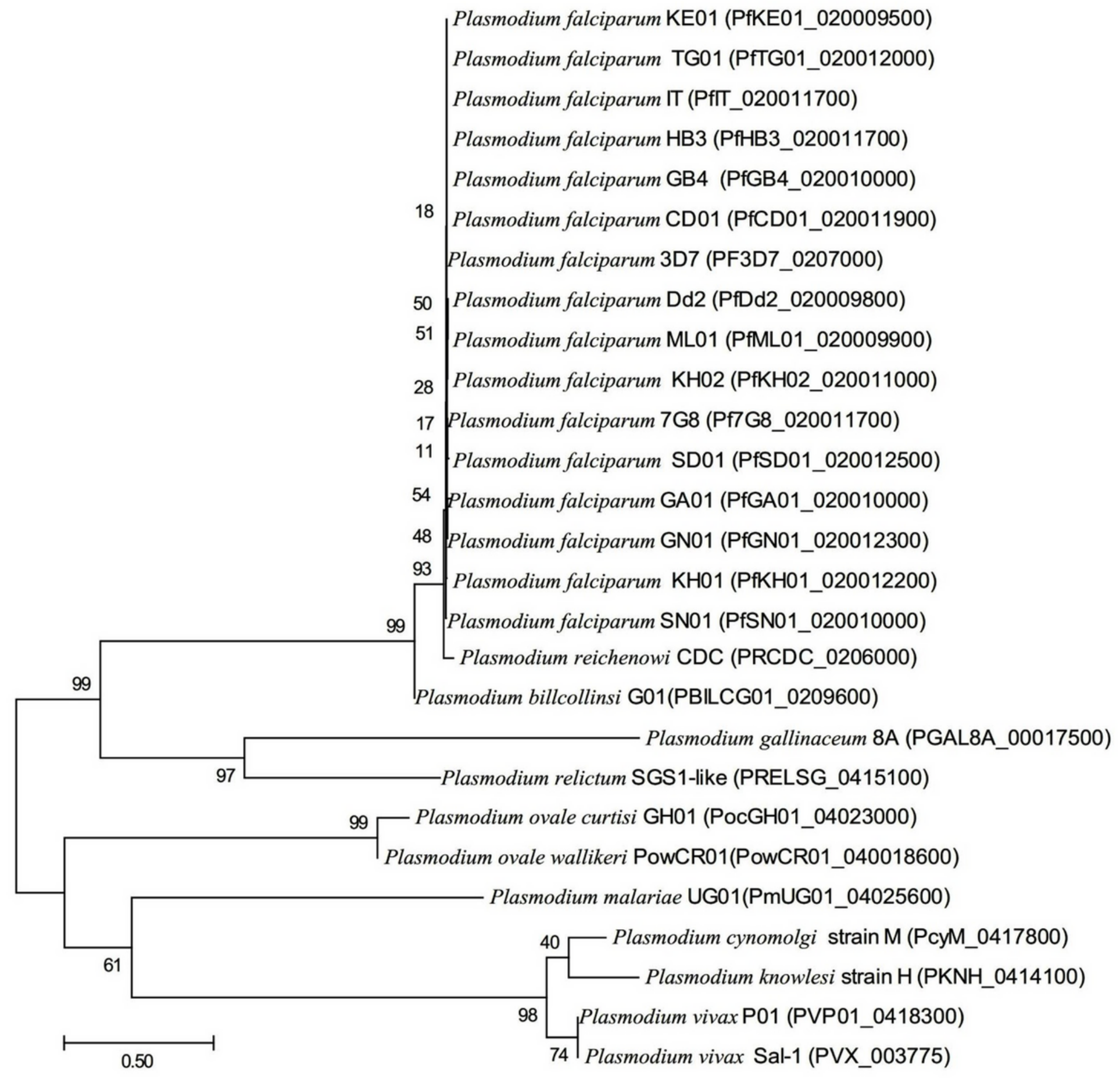

Figure 1

Phylogenetic analysis of msp4 gene sequences within orthologues in other Plasmodium species using the neighbor-joining method. The analysis of pocmsp4 and powmsp4 revealed 99\% similarity. 
a

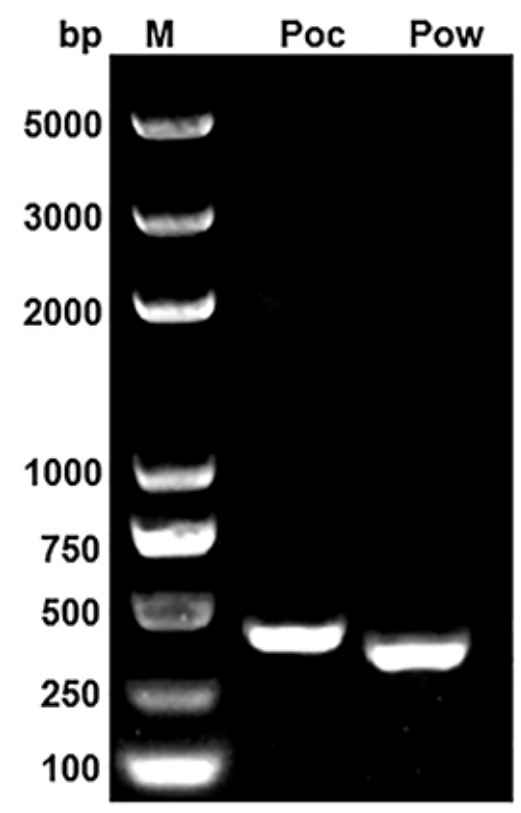

b

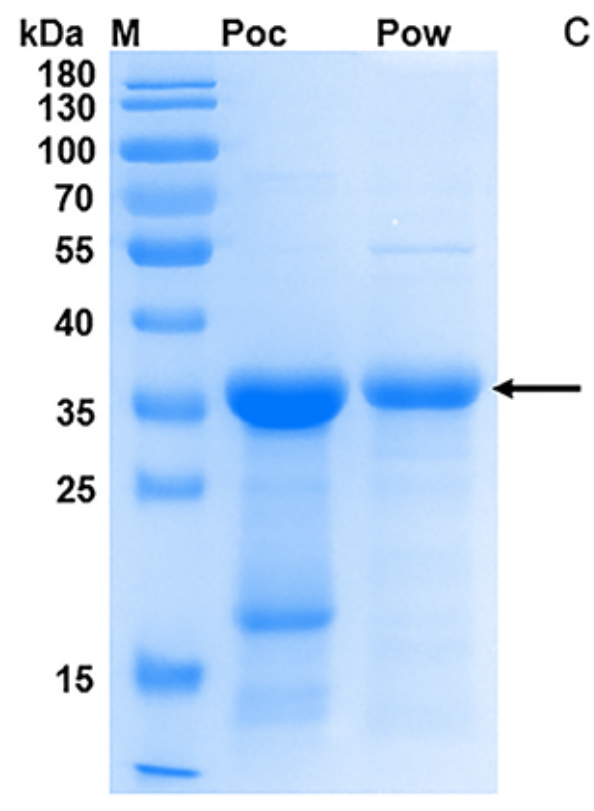

C

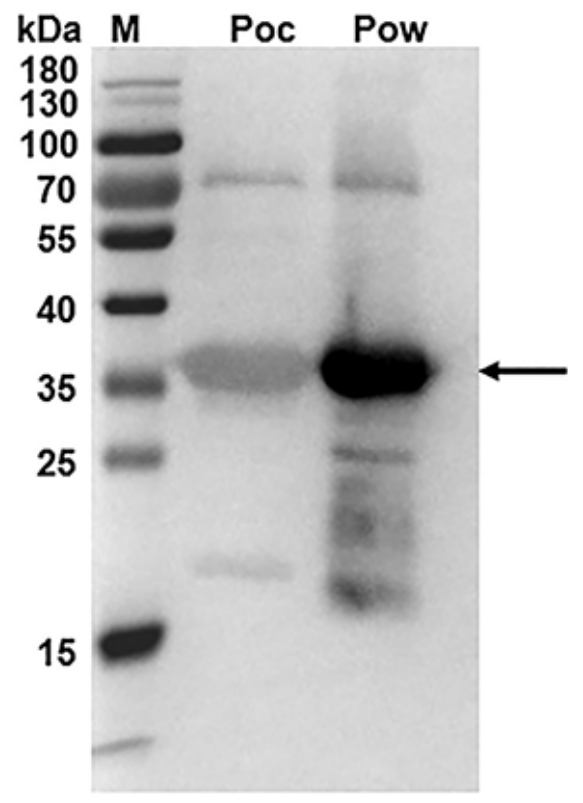

\section{Figure 2}

a Target genes of 46 P. ovale spp. isolates were amplified via PCR, and accurate sizes of 360 and $294 \mathrm{bp}$ were obtained for pocmsp4 and powmsp4, respectively. b Purified PoMSP4 proteins analyzed through SDS-PAGE with Coomassie blue staining. Analysis of rPoMSP4 showed that pocmsp4 and powmsp4 had a molecular weight of approximately $32 \mathrm{kDa}$. c Western blot analysis of rPoMSP4 using anti-His antibody indicated the specific bands. Molecular weight markers are indicated in kilodaltons (kDa). 

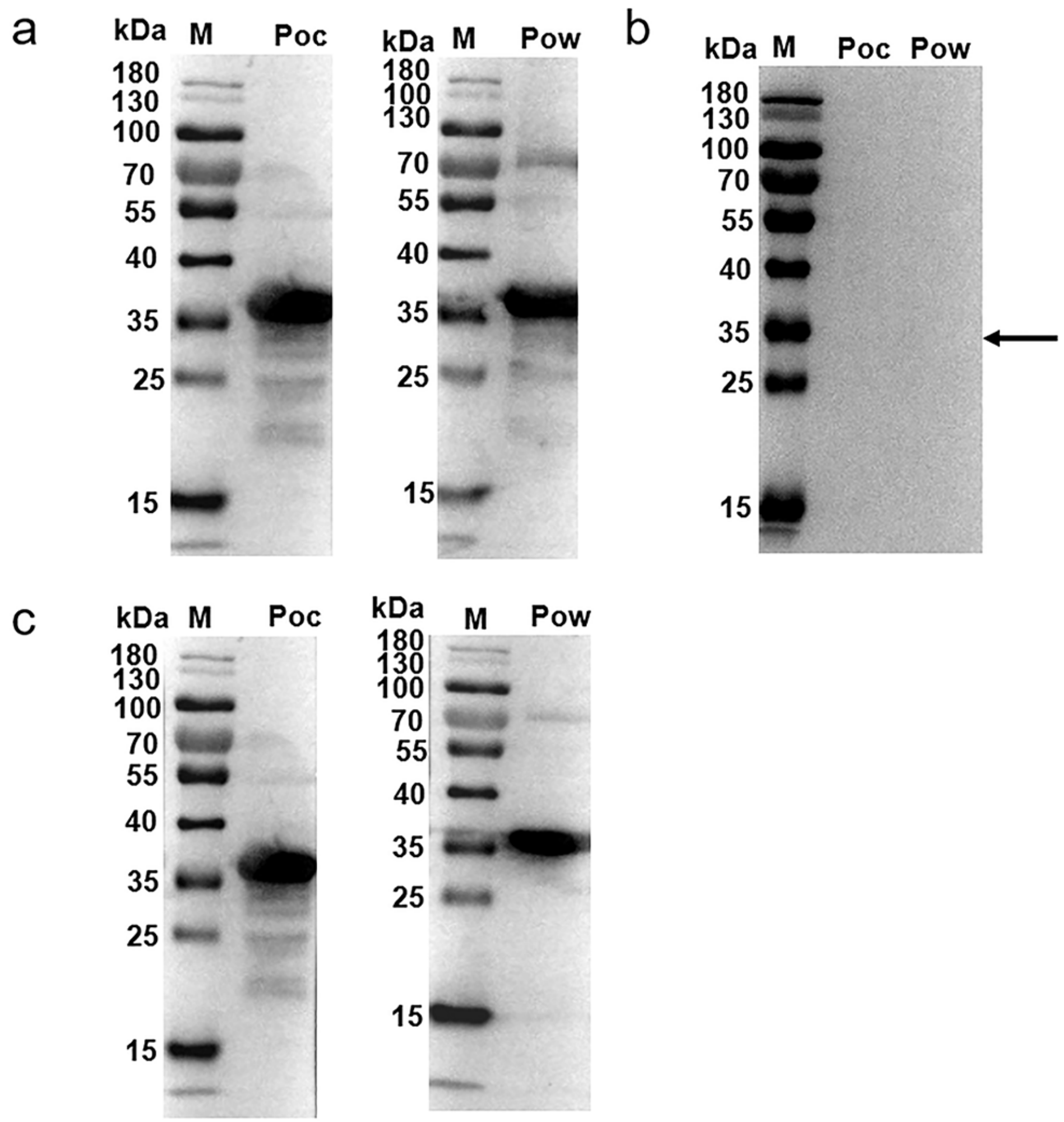

Figure 3

Reactivity of serum from mice immunized with rPoMSP4. a Western blot analysis for the detection of rPoMSP4 proteins using sera from mice immunized with rPoMSP4 proteins. b Sera from mice immunized with PBS and adjuvant as negative control. c Cross-reactivity of rPoMSP4 with sera of mice immunized with recombinant PoMSP4 was verified by Western blot. Molecular weight markers are indicated in kilodaltons $(\mathrm{kDa})$. 


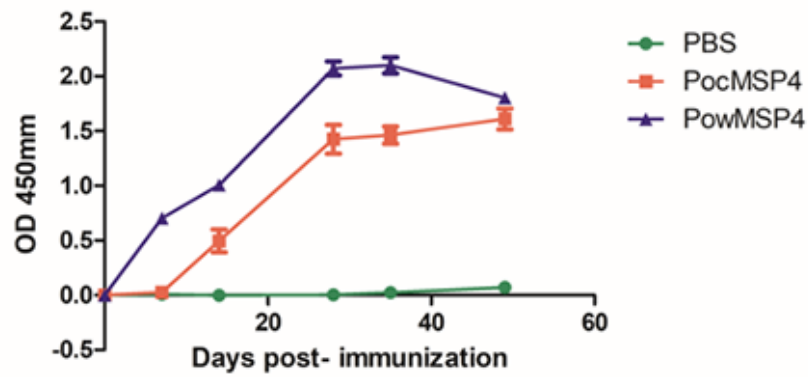

b

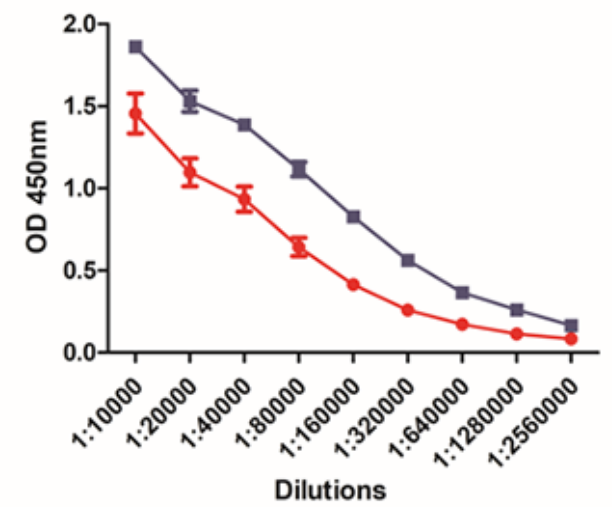

c

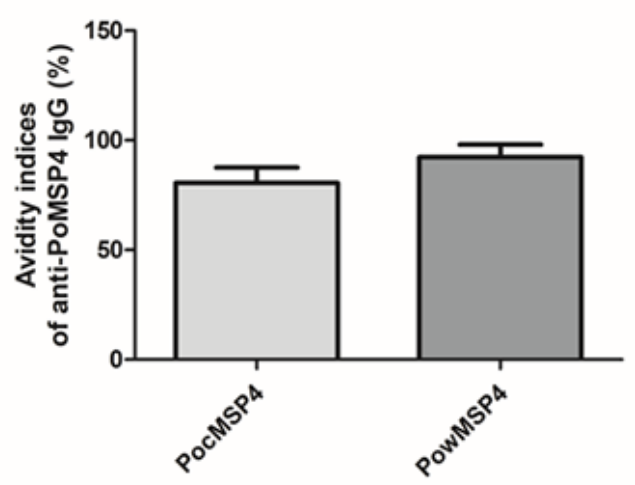

d

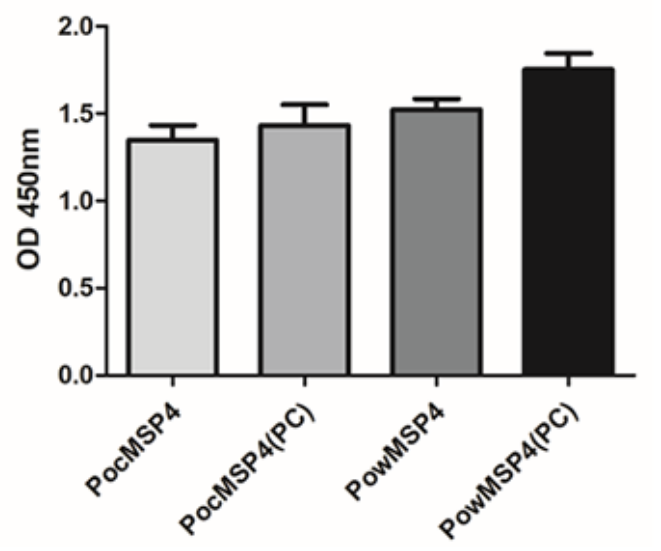

$\mathrm{e}$

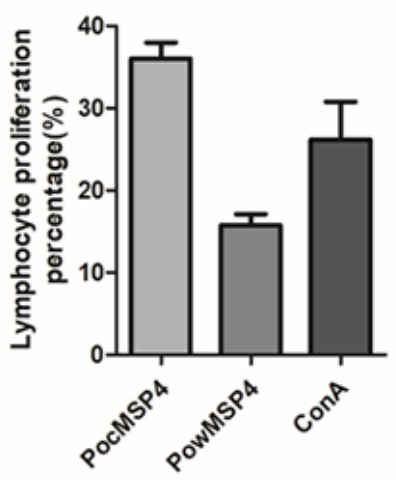

Figure 4

Immune response in mice immunized with rPoMSP4. a IgG was detected at day 7 post-immunization, and the levels continued to rise throughout the whole immunization period. b Immunized mice sera were diluted from 1:10,000 to 1:2,560,000. Data are presented as the geometric mean OD obtained at different concentrations. Numbers on the X-axis indicate the dilutions tested. Antigen specificity was confirmed using pre-immune serum samples as control. c Antibody avidity of rPoMSP4 was verified through ELISA. Antibody avidity was higher in PowMSP4 (mean 92.3) than in PocMSP4 (mean 80.5). d Cross-reaction of PocMSP4 with sera from mice immunized with rPowMSP4 proteins and cross-reaction of PowMSP4 with sera from mice immunized with rPocMSP4 (PC, positive control). e Splenocytes of immunized BALB/c mice were stimulated with $5 \mu \mathrm{g} / \mathrm{mL}$ of each recombinant protein used in immunization. The cells were stimulated for $72 \mathrm{~h}$. Data were measured at $450 \mathrm{~nm}$ and transformed in percentages of PocMSP4 (36\%) and PowMSP4 (15.8\%). 
a
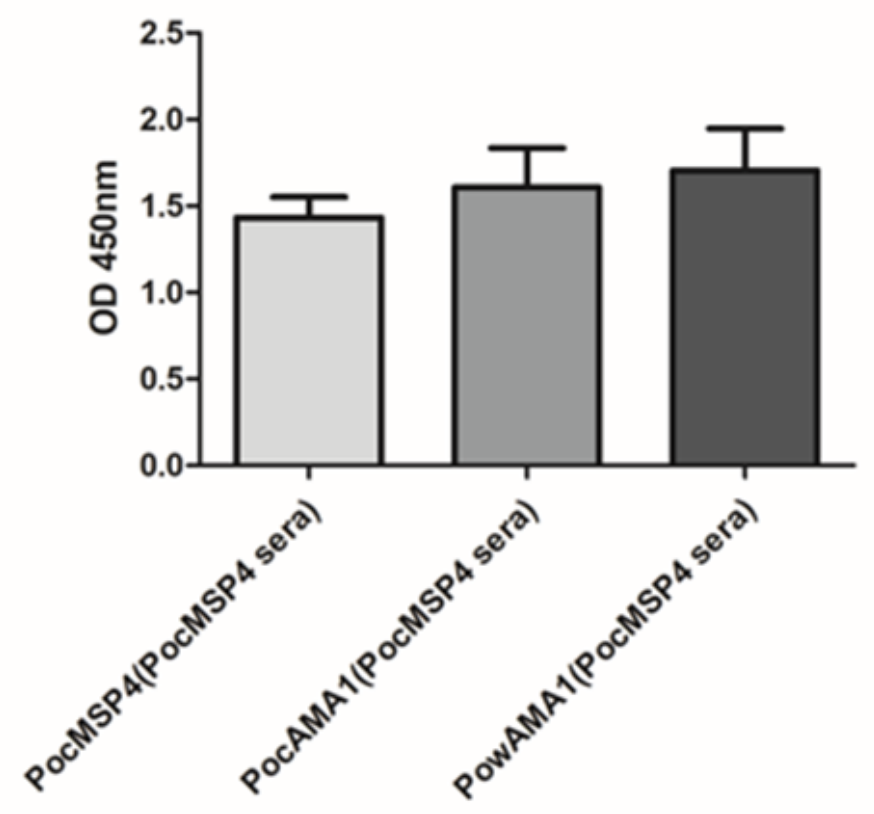

C

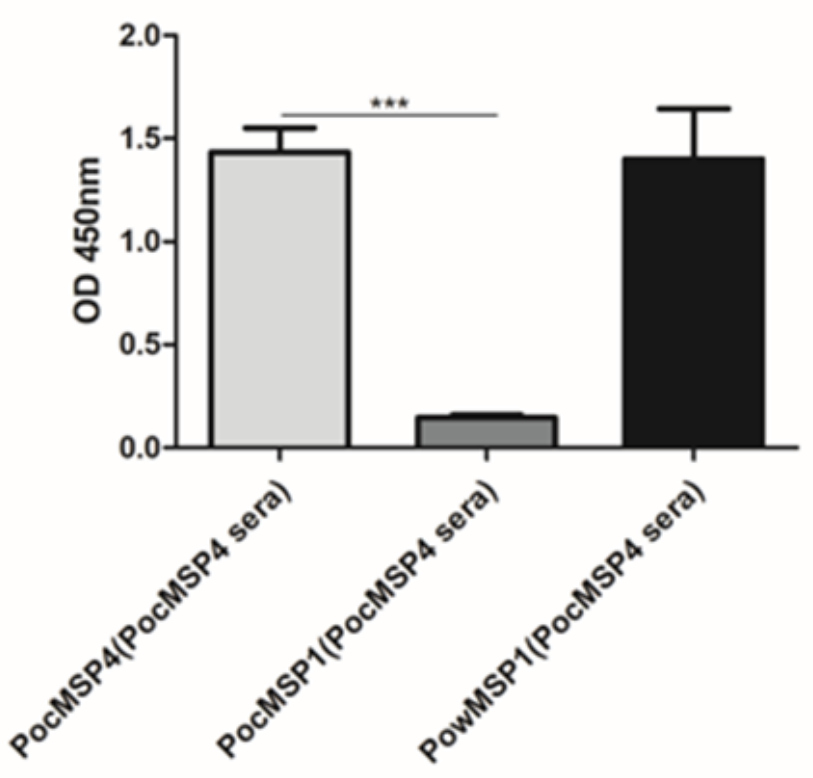

b
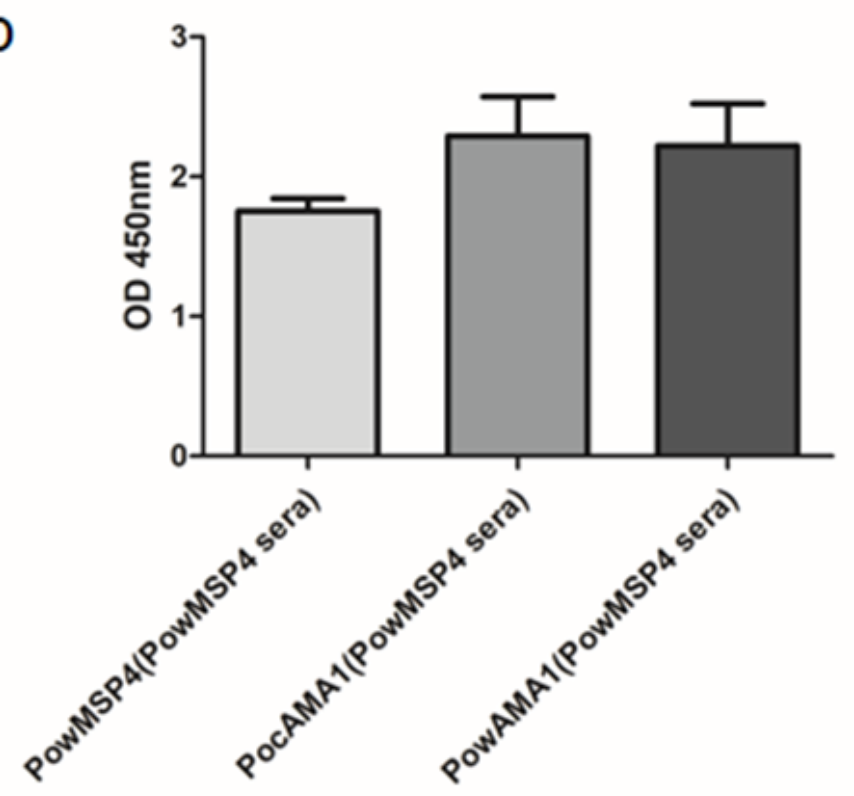

d
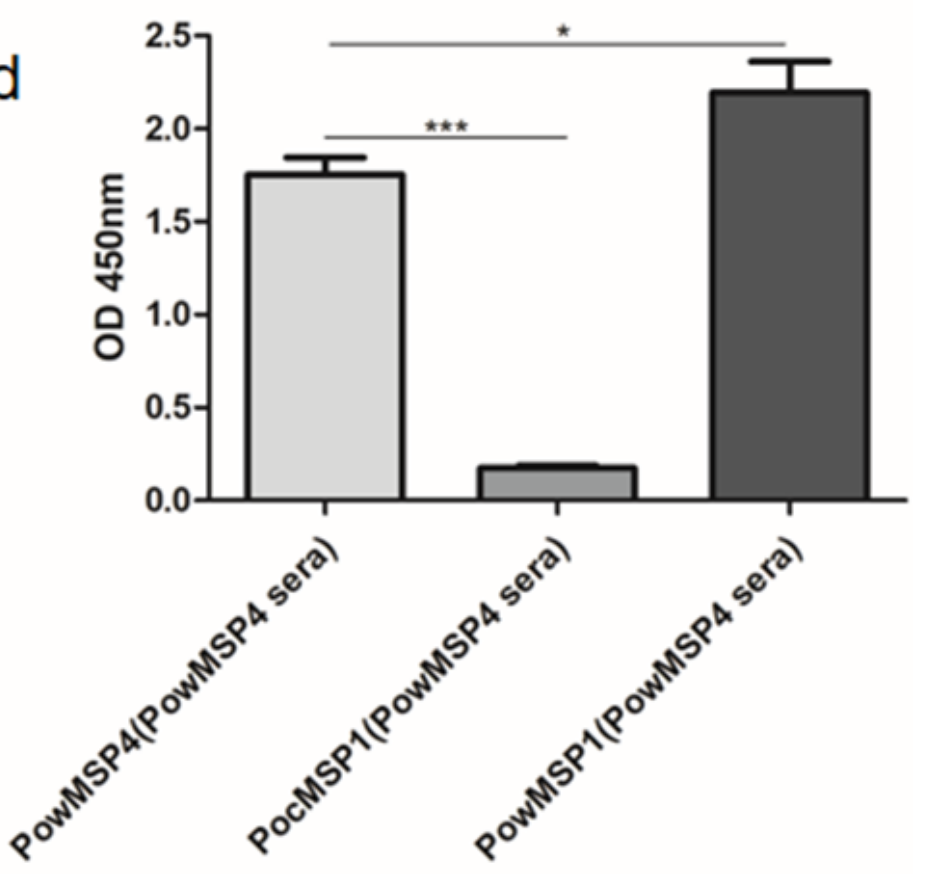

Figure 5

Specificity and reactivity of the sera of rPoMSP4-immunized mice using PoAMA1 and PoMSP1 proteins. The reactivity of sera from mice immunized with rPoMSP4 was evaluated using rPoAMA1 and rPoMSP1 proteins. a, b. Cross-reaction of rPoAMA1 proteins with antisera from mice immunized with rPoMSP4. No significant differences were observed between PocMSP4, PocAMA1, or PowAMA1 and the anti-PocMSP4 antisera and between PowMSP4, PocAMA1, or PowAMA1 and the anti-PowMSP4 antisera ( $>0.05)$. c, $d$ Cross-reaction of rPoMSP1 proteins with antisera from mice immunized with rPoMSP4. Significant differences between groups are indicated on the graph. No significant difference was found between rPocMSP4 and PowMSP1 to anti-rPocMSP4 sera $(p=0.9063)(c)$ and between rPowMSP4 and PowMSP1 to anti-rPowMSP4 sera $(p<0.0430)(d)$. 


\section{Supplementary Files}

This is a list of supplementary files associated with this preprint. Click to download.

- Additionalfile2FigureS1Poc.tif

- Tables2.docx

- Additionalfile1Tables1.docx

- Additionalfile2FigureS1Pow.tif 